\title{
Actuarial Assumptions for Employees Benefits
}

\author{
Tatiana Dănescu ${ }^{1}$, \\ Irina Diana Iordache ${ }^{2 *}$
}

\footnotetext{
${ }^{1}$ George Emil Palade University of Medicine, Pharmacy, Science, and Technology of Targu Mures, 38. Gh. Marinescu St., Târgu Mureș, 540139, România

2 "1 Decembrie 1918" University of Alba Iulia, 5 Gabriel Bethlen St., Alba Iulia 510009, Romania
}

\begin{abstract}
Entities that have assumed the obligation to provide benefits to employees both during employment and post-employment, in accordance with international regulations, in particular IAS 19 "Employee benefits", have the obligation to present to users 'financial payments and rights related to employees. The evaluation of the employees' benefits is based on actuarial techniques and on professional judgments that require the highlighting of the arguments underlying the identification and establishment of the actuarial hypotheses. To achieve this objective, we conducted research on how to select actuarial assumptions in the process of determining the benefits of employees in an entity in the energy field. The conclusions established highlight the role of the actuarial assumptions chosen in establishing the managerial vision on the obligations to be estimated for the personnel expenses, both present and in the future, in the context of the unpredictable evolution of the dynamics of the employees, as well as of economic circumstances created by constantly changing wage policies.
\end{abstract}

Keywords: 19 "Employee benefits", cost of current services, actuarial techniques, actuarial assumptions

\section{JEL Classification: M41}

(C) 2019 Publised by ACTA MARISIENSIS, SERIA OECONOMICA, Publisher University Press Târgu Mureș, issued on behalf of University of Medicine, Pharmacy, Sciences and Technology "George Emil Palade" from Tîrgu Mureș, România

\footnotetext{
* Corresponding author: Irina Diana Iordache, +40757997478

e-mail: irina.iordache07@gmail.com
} 


\section{INDRODUCTION}

The main objective of IAS 19 "Employee benefits" is to present a way of establishing the employee benefits and how to account them. This necessity derives from the contractual relation between the employer and the employee, in the sense that the employer assumes the responsibility to offer benefits to the employees in exchange for the providedservices.

In this respect, according to IAS 19, the entity has the obligation to evaluate and recognize a debtin their financial statements, representing the amounts to be paid in the future on the employees' benefits and a current expense that must impact the economic benefit as a result of the providedservice.

In order to evaluate the obligations regarding the benefits of the employees, in practice the most used method is the Projected Credit Factor Method. This method consists in determining the entity's obligations regarding the benefits of the employees by updating the value of the obligations and the cost of the current services.

When determining the final cost of granted benefits, it is absolutely necessary for an entity to know and clearly define its actuarial assumptions.

In the standard we find a multitude of hypotheses that could be used in the estimation models regarding the final cost of granted benefits, but we notice that in practice there are difficulties in choosing the most appropriate hypotheses depending on the specific activity. This aspect should not be neglected because a non-correlation of the actuarial assumptions can significantly distort the value of the debt recognized in the financial statements.

\section{DEFINING THE EMPLOYEES BENEFITS IN THE RESEARCH LITERATURE}

In June 2011, the International Accounting Standards Board (IASB) published a revised version of IAS 19 "Employee Benefits", a review that came into effect beginning of January 1st, 2013 reports (Deloitte, 2014).

Prior to this change, the provisions of the standard allowed the recognition of actuarial gains and losses arising from the obligations with the employees' benefits through the perspective of three approaches (Ernst \& Young, 2011b, p. 3):

- the recognition in other elements of the general result;

- immediate recognition in the profit and loss account;

- postponing recognition by profit or loss (the so-called corridor approach).

In contrast, the current form as a result of the last amendment to IAS 19 admits only an immediate recognition of actuarial gains and losses arising from employee benefit obligations in the form of provisions (Ernst \& Young, 2011b, p. 3).

Also, last year, the IASB introduced new amendments to IAS 19. They refer to the changes that have occurred in the plans of the entities for granting employees benefits and in this sense they are requiring the entities to revise the assumptions that have been made in the past and implicitly to recalculate the cost of current services and net interest for the rest of the reporting period.

Regarding actuarial assumptions, Bräuninger D. shows in a 2014 study by Deutsche Bank Research that the results of actuarial calculations were affected by demographic trends and changes at the macroeconomic level. The economic environment of today is defined by low interest rates, and this tendency directly influences the size of gains and losses resulting from actuarial calculations, as interest rates influence the discount rate required to update the value of the employee benefit obligation (Bräuninger, D., 2014, p.9).

Therefore, a low interest rate level leads to a reduced discount rate and in this case the present value of the obligation increases. In addition to interest rates, demographic trends in life expectancy significantly influence actuarial calculations for employee benefits, as longer life 
means longer periods that need to be covered by post-employment benefits (Towers Watson, 2015, p. 6).

The present study combines empirical research with theoretical research, through which we delineate the conceptual aspects of the chosen research.

The research addressed is an interdisciplinary one, referring to aspects that are found both in accounting, economic-financial analysis, statistics, as well as in the issue of economic modeling and actuarial techniques. In order to achieve the objectives, the issues will be discussed using a deductive reasoning from general to particular, combining qualitative elements with quantitative ones.

During this study we used various research techniques and procedures, among which: documentation on previous research, analysis of important normative acts, collecting and processing information, making tables, figures and graphs to synthesize and highlight the observations made.

\section{RESULTS OF THE RESEARCH}

The requirement to update the cost of employee benefits in accordance with IAS 19 would not be met if the entities did not identify and capture as many factors influencing the actuarial assumptions.

\subsection{Employees benefiyts}

In practice, entities provide benefits to employees in various forms, as a result of direct contractual negotiations or through trade union organizations.

Specifically, from the documentaries carried out on the practices of several entities, it was found that, at the level of an energy company we can meet besides a series of benefits, such as jubilees, life insurance, pensions, compensatory salaries depending on the degree of fidelity, other employee benefits, etc., also a benefit specific to the field arising from the legislative obligations, namely, granting for pensioners a free electricity quota of $1200 \mathrm{kWh} /$ year for their own household consumption. As a rule, these benefits are granted on the basis of certain conditions related to minimum working age in the energy field and the time of retirement.

\subsection{Actuarial asummptions}

For a better estimation of the benefits of the employees in the energy field it is absolutely necessary to know the most appropriate actuarial assumptions in this field.

According to the provisions of the standard and the best practices used, actuarial assumptions fall into two categories: financial hypotheses and demographic hypotheses (Figure no. 1).

Figure no. 1- Actuarial assumptions

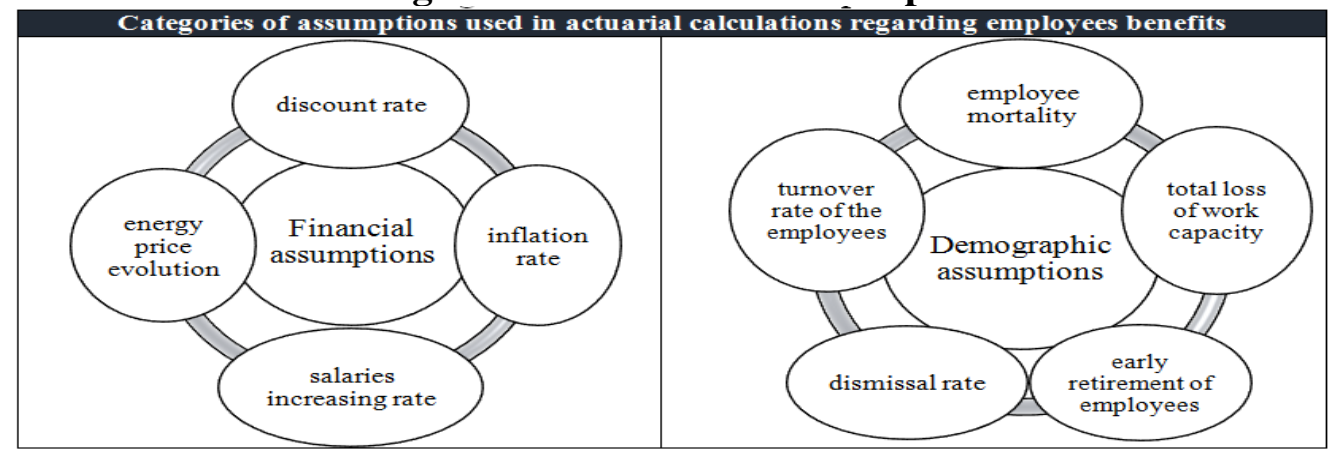

Source: authors`projection 
For example, in determining the obligation regarding the benefit of free electricity, it is very important to correctly estimate the energy price during the calculation and after this to update the cost of the benefit. Thus, throughout the discount period, the entity must take into account in the estimation model the consumer price index and know the evolution of the energy price in $\mathrm{kW}$ and the excise duty, to which the VAT is applied. In order to estimate the increase of the future prices, one starts from the price of the current period and the previous periods and with the help of the Forecast function in Excel, the linearly evolution can be determined. Finally in calculating the benefits regarding the free energy granted to the pensioners a weighted average of the $\mathrm{kW}$ price is required.

Where:

$$
P e=F O R E C A S T(X, \text { dependent variable, independent variable })
$$

$\mathrm{Pe}=$ Electricity price

$\mathrm{X}=$ The year of which the value is estimated for.

Within the entities in the energy field, for a year in which the price estimate is desired, it is possible to choose as the known dependent variable the historical values of the energy price, and for the known independent variable can be taken into account the matrix of the years related to these historical values. For example, in Table no. 1 we know the indices of the prices of the energy production for the last 5 years, according to the INS data. By applying the function Forecast in excel we can estimate an increase of the index of the price of the energy with approximately $11 \%$ for the year 2019 . Thus, following the estimation the price of energy is determined by the present value of the benefit of the employees regarding the granting of free electricity.

Table no.1 -Estimation of the energy price index in 2019
\begin{tabular}{|cc|} 
Year & Energy price index \\
\hline 2014 & 96.58 \\
\hline 2015 & 100.00 \\
\hline 2016 & 93.78 \\
\hline 2017 & 102.73 \\
\hline 2018 & 112.56 \\
\hline 2019 & 111.54 \\
\hline
\end{tabular}
Source: own processing based on INS database (2014-2018)

Such a hypothesis, according to the standard, could fall into the category of financial hypotheses (IAS 19 "Employee Benefits", https://www.iasplus.com/en/standards/ias/ias19). Other assumptions in this category used in the estimation models are: discount rate, inflation rate, wage growth rate, etc.

In estimating employee benefit obligations, in addition to the financial assumptions presented above, entities may also use a number of demographic assumptions regarding the characteristics of employees eligible for the appropriate benefits.

The demographic hypotheses are based on information and characteristics related to the eligible personnel included in the estimation model. In principle, these data refer to the updating of average rotation rates of employees by age groups, employees mortality, total loss of work capacity, partial early retirement of employees, dismissal rate, etc.

For example, regarding the mortality of the employees, the actuarial calculations use the mortality table of the population of Romania, structured on men and women, issued by the National Institute of Statistics (INS).

Often, the estimation of future costs of employee benefits depends mainly on the wage hypotheses corroborated with the demographic hypotheses, which mainly follow the life 
expectancy. By this indicator - the life expectancy - the expected number of years for which the annuities are to be paid is determined. This indicator is calculated based on the mortality tables found especially in the models used by the pension plans. From the existing statistical data there is an increase in life expectancy both at national and international level. According to Figure no. 2, in the European Union in 2050 the life expectancy will reach the level of 86 years, and in Romania it will be 81 years.

Figure no. 2 - Extrapolating life expectancy in Romania versus the EU

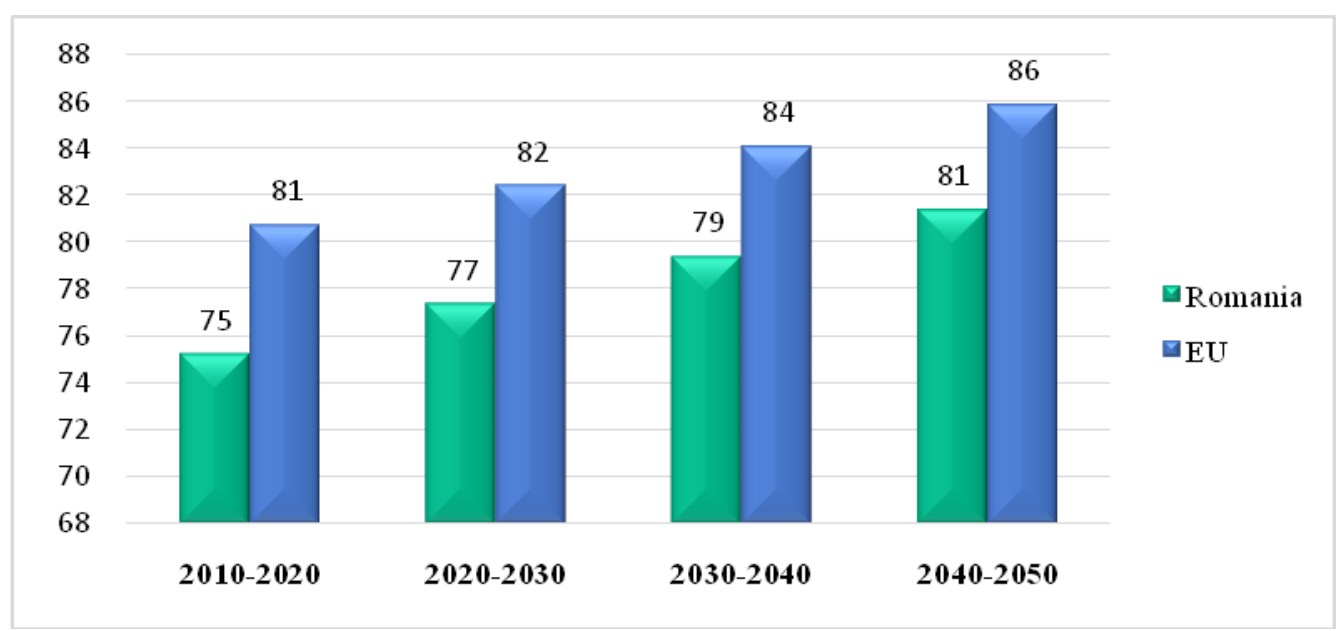

Source: own processing based on EUROSTAT database (2010-2018)

Regarding the life expectancy by gender, at the level of Romania, as observed in Figure no.3, women have a higher life expectancy than men, and this structure is also preserved in the long term.

Figure no. 3 - Extrapolating life expectancy in Romania by gender

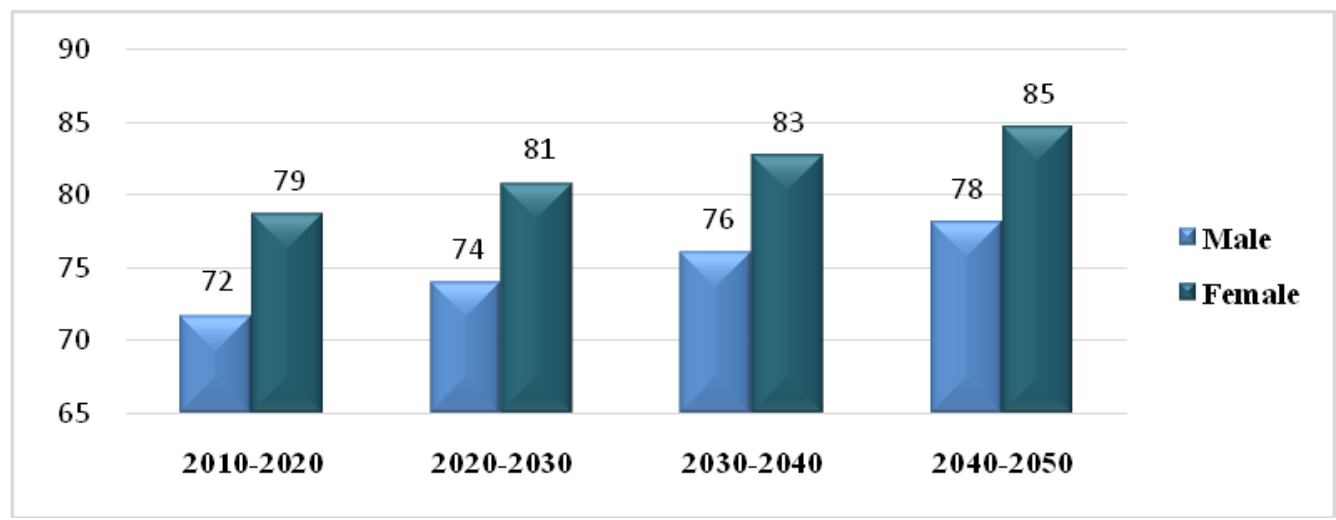

Source: own processing based on INS database (2010-2018) 
Life expectancy aspects are useful in estimating the period for which the cost of benefits is calculated for each employee both in the field of work and in the post retirement period.

In actuarial calculations, knowledge of life expectancy information would not be sufficient if it did not correlate with the mortality table, because at the same age, both employees and retirees have the same probability of dying. In the model of estimating the cost of benefits of each employee structured on homogeneous groups of ages and genders, the updated values of these benefits are weighted with these two indicators. For example, in Table no. 2 - extracted from Eurostat data, the correlation of the two indicators is observed, as follows: for a man aged 40 years the cost of benefits must be updated over a period of 44 years (life expectancy) influenced by the probability of death related to age (0.00052220).

Table no. 2 - The correlation of life expectancy with the probability of death by age categories

\begin{tabular}{|c|c|c|c|c|}
\hline \multirow{2}{*}{ Age } & \multicolumn{2}{|c|}{ Male } & \multicolumn{2}{c|}{ Female } \\
\cline { 2 - 5 } & Probability of dying at age $x$ & Life expectancy & Probability of dying at age x & Life expectancy \\
\hline 40 & 0,00052220 & 44 & 0,00040251 & 47 \\
\hline 45 & 0,00089611 & 39 & 0,00069129 & 42 \\
\hline 50 & 0,00151059 & 35 & 0,00118716 & 37 \\
\hline 55 & 0,00254589 & 30 & 0,00203834 & 32 \\
\hline 60 & 0,00428923 & 25 & 0,00349874 & 27 \\
\hline 65 & 0,00691083 & 21 & 0,00600232 & 23 \\
\hline 70 & 0,01268196 & 17 & 0,00923173 & 19 \\
\hline 75 & 0,02321581 & 13 & 0,01561910 & 15 \\
\hline 80 & 0,04230976 & 10 & 0,02977824 & 11 \\
\hline 85 & 0,07648061 & 7 & 0,05640000 & 8 \\
\hline 90 & 0,13322851 & 5 & 0,10771240 & 5 \\
\hline
\end{tabular}

Source: EUROSTAT database

Another demographic assumption is related to the average turnover of employees. This hypothesis is based on the history of the personnel structure by age groups at the level of each entity.

If we assume that in an entity the average turnover rate of employees by age groups in intervals of 10 years is the one in the table below (Table no. 3, columns 1-2) and knowing the weight that the employees in the respective age intervals areoccuping in the entity (Table 3, column 3), we can, with the help of the SUM and SUMPRODUCT functions in Excel (bellow ilustrated formula), determine a weighted average rotation rate for the current year. In the example below, this would be $5.7 \%$ (column 4 ).

Where:

$$
W a=S U M P R O D U C T(T p, W c) / S U M(W c)
$$

Wa $=$ weighted average

$\mathrm{Tp}=$ population turnover

$\mathrm{Wc}=$ weight of age groups at entity level

It should be noted that in our example for the last 5 years until retirement, we considered that the employees no longer seek to change their jobs and that they have accumulated enough experience not to be replaced on disciplinary or professional grounds. 


\section{sciendo}

ACTA MARISIENSIS, SERIA OECONOMICA

Online:ISSN 2668-3989, ISSN L 2668-3148

Print:ISSN 2668-3148, ISSN L 2668-3148

doi: 10.2478/amso-2019-0001

Tabel no. 3 -Example of calculating the weighted average of employee turnover

\begin{tabular}{|c|c|c|c|}
\hline Age ranges & Employee turnover & Weight at entity level & $\begin{array}{c}\text { The weighted average using the formula } \\
\text { in Figure no. 2 }\end{array}$ \\
\hline$(1)$ & $(2)$ & $(3)$ & $(4)$ \\
\hline $0-20$ & $50.7 \%$ & 1 & \multirow{2}{*}{$5.7 \%$} \\
\hline $21-30$ & $7.6 \%$ & 2 & \\
\hline $31-40$ & $4.8 \%$ & 3 & \\
\hline $41-50$ & $3.2 \%$ & 6 & \\
\hline $51-60$ & $5.3 \%$ & 4 & \\
\hline $61-65$ & $0.0 \%$ & 5 & \\
\hline
\end{tabular}

Source: authors`projection

The investigations used in choosing the actuarial hypotheses of the employees' benefits may surprise other situations found at the level of an entity, such as: early retirement, total loss of work capacity, dismissal rate, etc.

\section{CONCLUSIONS}

It can be observed that the results of any evaluation performed in the process of determining the cost of employee benefits depend significantly on how the actuarial assumptions are identified and used. Actuarial calculations should also be followed by the sensitivity analysis for each significant hypothesis, according to which entities can have multiple influences, including those related to concerns raised worldwide, such as population aging. A possible solution to counteract the effects of this phenomenon would be to encourage younger generations to stay longer in the labor market.

We consider that the importance of the actuarial hypotheses both in the primary process of estimating the obligation regarding the benefits of the employees and later in the sensitivity analysis, arises from the information obtained from the actuarial calculations that come to better define the managerial vision on the expenses with the present and future personnel, especially inan economy in which the dynamics of the employees is unpredictable.

\section{ACKNOWLEDGEMENTS}

This work is part of the project „Development of tertiary education in support of economic growth-PROGRESSIO", project code POCU/380/6/13/125040, project co-financed by the European Social Fund through the Human Capital Operational Program 2014 - 2020.

\section{Bibliography:}

BDO. (2016). IFRS AT A GLANCE. IAS 19 Employee Benefits.

Bräuninger, D. (2014). Institutions for occupational retirement provisions in Europe: ongoing challenges, Deutsche Bank Research.

A practical guide to implementing IAS 19 (2011) - Employee Benefits, 
Deloitte. (2014). Clearly IFRS, Moving ahead in an IFRS world - A practical guide to implementing IAS 19 Employee Benefits, disponibil la adresa: https://www2.deloitte.com/content/dam/Deloitte/ca/Documents/audit/ca-en-audit-clearly-ifrs-employeebenefits-ias-19-2011.pdf.

Ernst \& Young, (2011). Implementing the 2011 revisions to employee benefits.

Hannoun, H. (2015). Ultra-low or negative interest rates: what they mean for financial stability and growth. In Remarks by Hervé Hannoun, Deputy General Manager, Bank for International Settlements, at the Eurofi High-Level Seminar, Riga, Vol. 22.

Heim, M. \& Hilka, A. (2013). Discount rates low on the reporting date - what effect could this have on international accounting for pension liabilities? Frankfurt am Main: Allianz Global Investors Europe $\mathrm{GmbH}$.

Watson, T. (2015). Global Survey of Accounting Assumptions for Defined Benefit Plans - Executive Summary.

Statistical Yearbook of

Romania

http://www.insse.ro/cms/sites/default/files/field/publicatii/asr_2018_romana.pdf.

Eurostat database, https://ec.europa.eu/eurostat/data/database.

IAS 19 “Employee Benefits”,https://www.iasplus.com/en/standards/ias/ias 19. 